\title{
Pathways to enhanced value creation from the international technology transfer process in Thai construction projects
}

\author{
Tanut Waroonkun and Rodney A. Stewart \\ School of Engineering, Griffith University, Gold Coast Campus, \\ Queensland, Australia
}

\section{ALL CORRESPONDENCE TO:}

\section{Rodney A. Stewart}

Senior Lecturer

School of Engineering Griffith University Gold Coast Campus

PMB 50 Gold Coast Mail Centre QLD 9726, Australia

Telephone: (+61 7) 55528778

Facsimile: (+61 7) 55528065

Email:_r.stewart@griffith.edu.au

\author{
Dr Tanut Waroonkun \\ Assistant Professor \\ Faculty of Architecture \\ Chiang Mai University \\ 239 Huay Kaew Road, Muang District, Chiang Mai, Thailand, 50200. \\ Telephone: (+66 53) 942825 \\ Facsimile: (+66 53) 221448 \\ Email:_tanut@mail.arc.cmu.ac.th
}




\title{
Pathways to enhanced value creation from the international technology transfer process in Thai construction projects
}

\begin{abstract}
Purpose - International Technology Transfer (TT) initiatives are essential for developing the necessary infrastructure which underpins the sustainable development of economics and living standards in newly industrialised and developing countries. However, these initiatives have rarely translated into enhanced capabilities and competitiveness within host country firms, resulting in a sustained reliance on foreign firms. With few clues as to how to effectively manage the TT process, many stakeholders from the construction sectors of developing countries lack direction on how to more rapidly diffuse best-practice technology.

Design/ methodology/ approach - In an attempt to better understand the international TT process on Thai construction projects a path model was developed and later implemented. The path model development stage utilised the questionnaire survey response of 162 Thai construction and engineering professionals that had exposure to construction projects which incorporated international TT initiatives. A rigorous statistical analysis process which employed ANOVA, exploratory factor analysis, confirmatory factor analysis and structural equation modelling was followed to formulate the robust path model. The path model implementation stage utilised a series of case studies to validate the significant path equations in the developed model. This stage solicited questionnaire survey responses from 47 Thai construction and engineering professionals working for five domestic firms which were contractually involved with foreign partners on four large construction projects.
\end{abstract}

Findings - The findings provide evidence that transferors must have appropriate characteristics (i.e. willingness, knowledge base, experience, management, etc.) for establishing solid relationships with the transferee. Moreover, relationship building between the transferor and transferee (i.e. trust, understanding, communication, etc.) is the key enabler to TT induced value creation for the host construction sector.

Originality/ value - The developed model empirically explains interactions between TT process enablers and outcome factors in the construction context. The model will assist government and private sector organisations from developing and newly industrialised countries to better evaluate the TT induced value creation process for the host construction sector. Improved TT evaluation will help such organisations to devise targeted strategies for accelerating rates of TT, which will ultimately decrease their reliance on foreign firms when procuring large scale infrastructure projects. 
Keywords - Technology transfer, Developing countries, Thailand, Structural equation model

Paper type - Research paper

\section{Introduction}

In the past two decades (1987-2007) many developing countries, particularly in the Asian region have undergone unprecedented change in the construction sector. Many domestic construction firms have rapidly improved their management and technical capabilities through Technology Transfer (TT) initiatives with foreign firms (San, 2004). Several researchers have defined the TT term differently due to their individual fields of study. UNCTAD (1979) defined TT as the transfer of systematic knowledge for the manufacture of a product, for the application of a process, or for the rendering of a service. Chacko (1986) described TT in a scientific manner as converting physical/mental matter/energy into directly usable alternate form(s), and transfer means from one pocket into another pocket. In the construction sector, Simkoko (1992) attempted to build on this definition by identifying individual construction resources, as either materials or permanent equipment (e.g. steel beam, elevators, material) or construction-applied resources (e.g. information, skill). For the purpose of this study, international TT has been defined as when all types of knowledge relating to the construction field (e.g. design, construction process, material use, equipment utilisation, etc.) are transferred from a foreign party (transferor) to a host party (transferee) that arranges to receive it. In this research, the transferee refers only to Thai Architectural, Engineering and Construction (AEC) firms and the transferor refers to the foreign AEC firms working with Thai firms to procure projects. Numerous researchers have attempted to examine and/or model the international TT process (Calantone et al., 1990; Lin and Berg, 2001; Malik, 2002; Simkoko, 1992). A large portion of these studies were predominately focused on the business and manufacturing sectors. Some of these empirical and qualitative studies resulted in the development of a framework or model of the international TT process. However, none of these existing models can be immediately adopted to comprehensively explain interactions between TT process enablers and outcome factors in the construction context. 


\section{Conceptual Model}

In recent years, there have been many researchers that have studied and modelled the TT process, but few have targeted the construction sector. An extensive literature review was undertaken by the authors who closely examined existing TT models developed across all industry sectors and resulted in a conceptual model specifically designed for modelling the international TT process in the construction sector. Readers are referred to Waroonkun and Stewart (2007) for this critique of existing TT literature and the scholarly debate for the introduction of an international TT model for construction projects. This conceptual model included four process enabling constructs, namely, transfer environment, learning environment, transferor characteristics and transferee characteristics. The performance of and interaction between these enablers can influence the degree of value added to the host construction sector, in areas such as economic advancement, knowledge advancement and project performance (Figure 1). These constructs $(N=5)$ and their associated variables $(n=29)$ were customised for developing an international TT model in construction projects (see Table 1). This paper is predominately focused on quantifying the relationship between constructs in the conceptual model. To achieve this objective, Structural Equation Modelling (SEM) was utilised to establish path direction, coefficients and associated path equations. Following this, the validity of the developed path model was reinforced through case study investigations on four large construction projects where international TT initiatives were implemented. A complete description of the chosen research method for the study is provided in the following section.

\section{Research Method}

The research method for this project involved two key phases: (1) path model development; and (2) path model implementation. The first phase was concerned with developing an international TT model and associated prediction equations for evaluating the TT process on construction projects and the outcomes it derives for the host construction sector. The second phase aimed to evaluate the TT process on four large 
construction projects where international TT was incorporated and compare actual performance scores to those predicted by the standardised path equations developed in phase one of the research. Comparative analysis was conducted to reinforce the validity of the developed model. Each of these research phases are detailed below.

\section{Path Model Development}

Data collection for this study was undertaken from Thai construction professionals in the second quarter of 2005. The target group of respondents includes design and construction professionals from construction projects involving TT initiatives. This study only solicited the perceptions of transferees (Thai's) since TT initiatives are ultimately undertaken for the purpose of improving knowledge levels and enhancing the industry capacity of local (i.e. host) participants. Thus, individuals from host nations were considered to be the best respondents to evaluate the importance and effectiveness of variables pertaining to the TT process and the outcomes it can potentially generate. Understandably, it was difficult to determine the exact population of potential respondents fitting the description for this target group. However, this process was achieved through examining lists obtained from the Engineering Institute of Thailand, Council of Architects, Thai Contractors Association and through consultation with senior academics in Bangkok and Chang Mai. It was estimated that a population of 1100 project professionals across 35 design and construction projects were involved in international TT activities. A target sample of 300 was randomly selected from this estimated population. In total, 300 surveys were distributed and 162 were returned, representing a response rate of 54 percent. The questionnaire survey contained three distinct sections. The first section solicited descriptive statistics on the participating respondents and the past and present projects that they have been involved with where TT programs were integrated. This section enabled the establishment of a comprehensive respondent profile (i.e. experience, position description, etc.) and TT project profile (i.e. value, type, mode of transfer, etc.). Section two included questions relating to the enablers for successful TT, including: transfer environment; learning environment; transferor characteristics and transferee characteristics. Section three focused on measuring the outcomes of the TT process in the following categories: economic advancement; knowledge advancement; and project performance. Sections two and three contained a total of 29 questions representing all the variables in the conceptual model (Table 1). 
Respondents were requested to provide a rating for these variables in two separate columns (A and B) measured on a five-point Likert scale. Column A asked respondents for their opinion about statements related to TT, ranging from ' $1=$ strongly disagree' to ' $5=$ strongly agree'. For example, the respondent was requested to rate whether they believed mutual trust will help to create a good relationship between the transferor and transferee. These results were used to determine the importance/significance of each variable. Column B sought to ascertain respondents' perception of the successfulness/effectiveness of TT factors in the construction environment, based on their experience. For example, respondents were requested to rate the effectiveness/success of 'mutual trust' on projects they have been involved in where international TT was incorporated. The scale of column B ranged from ' $1=$ strongly negative' to ' $5=$ strongly positive'. These results were essential for determining the effectiveness of TT in the Thai construction industry. Moreover, they enabled causal links between variables to be established. In summary, the data set obtained from Column A was utilised to ensure that variables were perceived to be sufficiently important to be considered as essential TT enabler and outcome variables (i.e. mean greater than three). The data set obtained from Column B examined the successfulness/effectiveness of such TT variables and was utilised for evaluation purposes, formulating TT constructs and determining causal paths. Statistical techniques including exploratory factor analysis, confirmatory factor analysis, structural equation modelling and path analysis were adopted for this purpose.

\section{Path Model Implementation}

Following the development of the path model the authors sought to apply developed path equations on current Thai construction projects where international TT was incorporated. This research phase was essential to verify the validity of derived path equations through a comparative analysis of actual and predicted results. The target group of respondents comprised Thai construction and engineering professionals who were involved on a current (at time of survey) international TT construction project with a foreign partner in which some form of technology (e.g. management skills, construction techniques) was transferred. Model validation case studies were carried out in June 2006 with construction professionals in Thailand. In total, 55 targeted surveys were distributed and 47 were returned with $9,10,11,9$ and 8 respondents 
participating from five companies numbered 1,2, 3, 4 and 5 respectively, representing a response rate of 85 per cent. Company names have not been provided for confidentiality reasons.

The questionnaire survey design for the case studies was based around the sub-factors which represent the three significant paths identified in the primary study (transferee characteristics (TE) $\rightarrow$ transferor characteristics (TR); transferor characteristics (TR) $\rightarrow$ relationship building (RB); and relationship building $(\mathrm{RB}) \rightarrow$ TT value added (VA)). However, a further literature review was undertaken to break down the established sub-factors into a series of TT performance indicators (see Waroonkun, 2007). This questionnaire survey contained two distinct sections. The first section enabled the establishment of a comprehensive respondent profile (i.e. experience, project description, position description, etc.) for the case study participants. Section two contained a total of 40 questions relating to the sub-factors of the three significant paths. Respondents were requested to provide a rating for each TT performance indicator in the questionnaire survey measured on a five-point Likert scale. Specifically, the questionnaire asked respondents for their opinions about statements related to the sub-factors and associated indicators associated with the three significant paths, ranging from ' $1=$ very low/very poor' to ' $5=$ very high/very good'. The following two sections describe the analysis process and results for the path model development and implementation phases of the research study.

\section{Path Model Development: Primary Analysis}

\section{Respondent Profile}

The respondents were classified into six position categories: project manager (16\%); site engineer (40\%); consulting engineer (16\%); construction manager/foreman (16\%); architect (11\%); and other (1\%). The type of organisation they were employed in included: main contractor (43\%); sub-contractor (20\%); consultant (35\%); and other (2\%). The respondents' age break down was: under 30 years (20\%); 30-40 years (37\%); $40-50$ years (36\%); and over 50 years (7\%). Their construction experience break down was: 0-5 years (24\%); 6-10 years (19\%); 11-15 years (24\%); 16-20 years (17\%); and over 20 years (16\%). Evaluating education levels was necessary to demonstrate that the respondents were sufficiently educated to develop a professional 
opinion about the construction industry. If, for example, there were a high frequency of respondents with only a high school education, the results obtained may carry questionable authority and may not be submissible as an accurate and valid interpretation of the TT process. Fortunately, the highest frequency of respondents had a bachelor degree (61\%). Masters degree qualified respondents were also quite common (28\%), followed by diploma qualifications $(9 \%)$ and doctoral degree (1\%). Very few respondents had less than a tertiary education in the AEC field (1\%).

\section{Rating TT variables}

As previously described, the questionnaire respondent was required to rate their opinion for 29 items on a 5point Likert scale for two different aspects (column A: importance/significance; and column B: success/effectiveness). Table 1 details the mean and standard deviation value (columns A \& B) for each variable in the conceptual model.

The significant outcomes of the descriptive assessment for the importance/significance and success/effectiveness questionnaire items are summarised below:

- The mean values for all variables in column A were greater than three (3.0) indicating that respondents perceived that the entire set of variables contained in the questionnaire were important.

- Transferor characteristics (3.97) were considered to be the most important TT process enabler. However, transferee characteristics (3.93) and the learning environment (3.84) were also considered almost equally important. Perhaps due to respondents' limited understanding on the impact of macro factors on the TT process, the transfer environment construct (3.44) was not considered to be as important as the others.

- Understandably, communication (4.28) was considered to be the most important variable. Surprisingly, involving sub-contractors in the TT process (3.28) and the construction mode of transfer (3.36) were considered the least important enabling variables. 
- Most of the TT value creation variables were deemed highly and equally important. Respondents perceived that the implementation of TT programs was essential for improving quality standards (4.01). Since quality standards in developing countries are generally perceived to be quite low this result is not surprising. However, the importance of TT for improving the financial performance of host firms was notably lower (3.47) than the other outcome variables.

- Based on their experience, the respondents rated transferor and transferee characteristics as being the most successful enablers (3.63). Adversely, they thought that the transfer environment was the lowest performing enabler (3.29).

- Communication was not only perceived as the most important variable but was also rated as the most effective (3.92). This result is promising, considering the variety of nationalities involved in TT projects in the Thai construction sector. Dealing with cultural differences had the lowest success value (3.03). It seems that both the transferor and transferee have no problems communicating and working together in a professional environment but failed to (or don't want to) empathise with the other nationalities cultural make-up.

- Overall, the respondents indicated that TT was creating moderate to high value for the host sector. However, they did not believe that TT initiatives were providing substantial contributions to improved financial outcomes (3.24) for their firms.

The variables within all constructs were considered important (i.e. $>3$ ), therefore, a total of 29 variables was utilised for the initial factor analysis computation.

\section{Exploratory factor analysis}

Exploratory principal component factor analysis, with varimax rotation, was conducted to condense the information contained in the original 29 variables into a smaller set of factors with a minimum loss of information (Hair et al., 1998; Hatcher, 1994). Specifically, the aim was to search for and define the fundamental constructs assumed to underlie the original variables. The data sample was deemed adequate for factor analysis, exceeding the observation to variable ratio (i.e. 5.6:1) recommended by Hair et al. (1998). Moreover, the value for the Kaiser-Meyer-Olkin measure of sampling adequacy was 0.84 , exceeding the recommended threshold level of 0.5 (Coakes, 2005). Exploratory Factor Analysis (EFA) retained a 20 
variable solution, removing a total of 9 variables. Two of the removed variables (i.e. culture and training) had very high loadings within their own individual constructs. These factors could be argued as being essential enablers in the TT process; however, they were removed because they were factors which consisted of only one generic variable.

Eight (8) factors best represented the data in terms of variance explained (77\%) and grouping of variables. These factors included: (1) technology characteristics; (2) government influence; (3) relationship building; (4) transferor characteristics; (5) transferee characteristics; (6) economic advancement; (7) knowledge advancement; and (8) project performance. Table 2 details the factor loading, explained variance, eigenvalues and Cronbach's alpha for the eight-factor solution. All factor loadings exceeded the 0.5 threshold level with loadings ranging from 0.64 to 0.90 . Additionally, Cronbach's alpha results ranged from 0.57-0.86 indicating that the scale used was reliable (Fang et al., 2004; Hatcher, 1994; Zain et al., 2005). The results underline that the transferor characteristics factor is the key enabler of the TT process explaining almost half $(35 \%)$ of the total variance in the data set $(77 \%)$. The combined explained variance for the project-level enablers (i.e. transferor and transferee characteristics, relationship building) equates to more than two-thirds $(53 \%)$ of the total variance $(77 \%)$. These are undoubtedly, the factors that need to be carefully managed to ensure that the TT process derives the most value for the host country.

INSERT TABLE 2

The last three of these factors (6-8) are related to the outcomes derived from TT, and each contained only two variables. These factors would be better represented as one broader outcome factor, as originally perceived in the conceptual model (Figure 1). To verify this, factor analysis was performed on these three factors (6 variables). As suspected, only one factor resulted, explaining 55.7 percent of the variance and all loadings exceeded 0.6 (Table 3). Thus, factor analysis produced an international TT model consisting of six factors, including, five enablers: (1) Technology Characteristics (TC); (2) Government Influence (GI); (3) Relationship Building (RB); (4) Transferor Characteristics (TR); (5) Transferee Characteristics (TE); and one outcome factor: (6) TT Value Added (VA). The following stage of analysis utilises Structural Equation Modelling (SEM) to confirm the model structure and causal paths between factors. 


\section{Confirmatory factor analysis}

Confirmatory Factor Analysis (CFA) was undertaken to corroborate findings determined through EFA. The measurement model for these six constructs (latent variables) had acceptable goodness-of-fit indices: RMSEA $=0.048$, GFI $=0.90$, CFI $=0.96$, TLI $=0.95$ (Ragu-Nathan et al., 2004; Zain et al., 2005). Moreover, the results indicated that the items used for each factor were representative of that factor (regression weights $>0.5$, significant $t$-value at the 0.05 level), with some exceptions (Table 4). Variables related to the technology characteristics factor (construct) were problematic. The construction mode of transfer variable had a low regression weight (0.38) whilst the complexity level variable was only marginally significant $(t=1.64, p=0.1)$. Moreover, the regression coefficient for the latter variable was high (1.06) with excessive standard errors evident, indicating multicollinearity. EFA determined that the technology characteristics factor was reliable but provides some hints it could be problematic (Cronbach's $\alpha=0.57$; Variance explained $=3.53 \%$ ). In summary, CFA did not support the retention of the technology characteristics factor and it was removed from the SEM. CFA was again undertaken with the remaining five (GI, RB, TR, TE and VA) factors and their associated variables. The results indicated that the items used for each factor were representative of that factor (regression weights $>0.5$, significant $t$-value at the 0.01 level). The revised measurement model for these five constructs (latent variables) also had acceptable goodness-offit indices: $\mathrm{RMSEA}=0.046, \mathrm{GFI}=0.90, \mathrm{CFI}=0.97, \mathrm{TLI}=0.96$. The revised model was utilised for path analysis in the following section.

\section{INSERT TABLE 4}

\section{Path analysis}

Paths analysis was undertaken using the SEM technique to uncover the significant interrelationships between the factors retained from EFA and CFA. From the analysis it was determined that government influence was 
the only exogenous $(\gamma)$ factor in the model. The remaining enablers were considered to be endogenous factors $(\beta)$. The causality relations considered are non-recursive. Moreover, discriminate validity analysis did not uncover any correlated endogenous perspective (Anderson and Gerbing, 1988; Kaynak, 2003). Additionally, scatter plots between the five factors were conducted to ensure that a linear trend best represented (i.e. highest $R^{2}$ fit) their relationship. Figure 2 presents the formulated path model for international TT in construction projects. This model has the following fit coefficients: CMIN/DF $=1.34$, RMSEA $=0.046, \mathrm{GFI}=0.90, \mathrm{AGFI}=0.87, \mathrm{NFI}=0.88, \mathrm{CFI}=0.97, \mathrm{TLI}=0.96 . \mathrm{In}$ total, four structural equations explained the five causal relationships (paths) which exist between the five retained TT enabling and outcome factors. It should be noted that whilst government influence was denoted as a significant predictor $(p<0.05)$ of transferee characteristics $(\mathrm{GI} \rightarrow \mathrm{TE})$ it explained only a fraction of the variance in this factor $\left(R^{2}=0.04\right)$. This may be due to the fact that respondents had widely varied perceptions on the impact of government policy and enforcement, based on their sector-specific experiences. A summary of the developed structural equations, path coefficients and significance levels is provided in Table 5. The following section describes the implementation of the developed path model on a series of case studies.

INSERT FIGURE 2

INSERT TABLE $5=$

\section{Path Model Implementation: Case Studies}

The three significant paths determined from SEM were selected for validation, namely: transferee characteristics (TE) $\rightarrow$ transferor characteristics (TR); transferor characteristics (TR) $\rightarrow$ relationship building $(\mathrm{RB})$; and relationship building $(\mathrm{RB}) \rightarrow \mathrm{TT}$ value added $(\mathrm{VA})$. These three paths were identified through SEM as having the highest contribution (i.e. standardised path coefficient $>0.5$ ) to TT value creation for the host construction sector of developing countries. The following reasons are offered to support the selection of these three significant paths for model validation. Firstly, as shown in Table 5, the government influence perspective was a low significance predictor of the transferee characteristics perspective $(p<0.05)$. Specifically, the government influence perspective only explains four per cent of the variance in the transferee characteristics perspective. Secondly, the target group of respondents only included Thai design 
and construction professionals working in construction projects, which involved TT initiatives. If the path model validation involved the government influence perspective, the target group of respondents would have also needed to include senior executives and government officers that may have a better comprehension on the impact of government policy and enforcement practices on the TT process.

Figure 2 highlights the three significant paths selected for validation and their associated standardised and unstandardised path coefficients. Similarly, Table 5 includes the adapted structural equations, path coefficients and significance levels for these three paths. The objective of this research phase was to compare both raw and predicted mean values obtained from the primary study and the five case studies. Firstly, the raw mean values are compared and discussion provided for significant differences. Secondly, the developed path equations were utilised for predicting the mean values for dependent factors for the five case studies. Subsequently, the actual values for the case studies were compared against predicted values and significant variances discussed. A full description of the analysis process and results obtained for the case studies is provided in the following sub sections.

\section{Case Studies Profile}

It should be noted that only basic details of the case studies and their respective participants are provided due to confidentiality requirements. Four international TT construction projects involving five construction companies in Thailand were selected for the case studies $(N=5)$. Three of these construction projects were valued in excess of 300 million AUD and another one was valued around 30 million AUD. It should mentioned that companies number 1 and 3 worked on the same construction project acting as consultant and contractor, respectively. Moreover, a comprehensive list of TT performance indicators was developed for identifying and measuring the significant TT enabling and outcome factors (RB, TE, TR and VA) and their respective sub factors. However, the collected mean and standard deviation values for each TT performance indicator are not detailed herein; only the summary for factors and sub factors (see Table 6). Finally, readers should be informed that the respondent samples obtained from the five case studies were not intended to be of a sufficient size to undertake any complex exploratory statistical analysis. Their intended purpose was to reinforce the validity of the developed path model and associated equations produced from the in-depth 
primary study data analysis process. Therefore, only a small sample was collected for Company 1 through to 5 (i.e. $\mathrm{C} 1, \mathrm{n}=9 ; \mathrm{C} 2, \mathrm{n}=10 ; \mathrm{C} 3, \mathrm{n}=11 ; \mathrm{C} 4, \mathrm{n}=9$; and $\mathrm{C} 5, \mathrm{n}=8$ ).

\section{Comparing Actual Mean Values}

Table 6 presents the mean and standard deviation values for the four applicable enabling and outcome factors for the primary study and five company case studies. The mean values obtained from these studies were compared and are discussed in the following paragraphs. The purpose for making such comparisons was to uncover underlying impediments or critical success factors that may have resulted in above or below average factor values on particular case studies, respectively.

The respondents indicated a low rating for the communication variable at company 3 (RB3: 2.94) and company 5 (RB3: 2.92) when compared with the primary study (RB3: 3.92). These lower mean values for these two companies indicate that both the transferor and transferee seemed to have less effective communication when working together. The respondents from these two companies were working with Japanese transferors. Perhaps due to the Japanese transferor's lower proficiency in the English language (i.e. designated project language), the Thai respondents may have had more difficultly in understanding them, when compared with the wide variety of transferor nationalities examined in the primary study (i.e. Japan, United Kingdom, Australia, United State of America, Germany, etc.).

The mean values for transferor management in company 1 (TR3: 2.96) and company 3 (TR3: 2.94) were also lower than that from the primary study (TR3: 3.61). As previously mentioned, these two Thai companies worked in different roles on the same construction project. This suggests that the Thai respondents may have been concerned with the transferor's management practices and approaches on this project. Specifically, regarding company 3 , the respondents working with Japanese transferors rated low mean scores in both communication (RB3: 2.94) and transferor management practices (TR3: 2.94). These results may suggest that by having poor English language communication skills the Japanese transferors may have also found it difficult to display appropriate management practices for effective TT (i.e. leadership style, ego, etc.). It should also be noted that the respondents rated low mean scores in both financial and schedule performance 
at company 1 (PP1: 2.67, PP2: 2.56) and company 3 (PP1: 2.82, PP2: 2.45). These mean scores were not surprising due to the government payment delays leading to the late project completion.

INSERT TABLE 6

\section{Determining Predicted Factor Values}

To reinforce the validity of the structural model a comparative analysis between the collected actual mean value for each applicable perspective (TE, TR, RB and VA) and the predicted value derived from the path standardised prediction equations was conducted. To achieve this, actual values obtained from the case studies were converted to an equivalent $Z$ score on the original Thai construction sector-wide distribution established in the primary study (Table 7). For example, the calculated $Z$ score for the TE factor in company $1(\mathrm{CO} .1)$ was $Z_{\mathrm{C} 0.1, \mathrm{TE}}=(3.42-3.60) / 0.78=-0.23$. Similarly, the $Z$ scores of other factors for company 1 were $Z_{\mathrm{C} 0.1}$, $\mathrm{TR}=-0.49, Z_{\mathrm{C} 0.1},{ }_{\mathrm{RB}}=-0.51$ and $Z_{\mathrm{C} 0.1}, \mathrm{VA}=-0.49$. For the prediction of $Z$ scores for each factor in each company, single $Z$ scores or combinations were utilised in the appropriate standardised equations presented in Table 5. For example, the actual $Z_{\mathrm{C} 0.1}$, TR score of -0.49 was substituted into the RB prediction equation (i.e. $Z_{\mathrm{C} 0.1, \mathrm{RB}}=0.81 Z_{\mathrm{C} 0.1}$, TR $)$ to establish a predicted $\mathrm{RB}$ factor $Z$ score for company 1 (i.e. $Z_{\mathrm{C} 0.1}$, RB $=0.81 \times-0.49=-0.40$ ). Table 7 shows the equivalent $Z$ scores and the predicted $Z$ scores for each factor for each respective company. Subsequently, these predicted $Z$ scores were equated to raw predicted values for comparative analysis purposes as described in the following section.

\section{INSERT TABLE 7}

\section{Comparing Actual and Predicted Mean Values}

From Table 7 , for company 1 , the calculated $\mathrm{RB} Z$ score $\left(Z_{\mathrm{C} 0.1}, \mathrm{RB}=-0.40\right)$ equates to a predicted strategic competitiveness mean value of 3.25 , representing a difference of 0.10 or 3.17 percent from the actual collected value (Table 8). The predicted RB mean value for company 1 (i.e. $\mathrm{RB}=3.25$ ) was calculated based on the mean RB value from the primary study and the predicted standard deviations from this mean as shown 
in Table 7 (i.e. $3.62-[0.40 \times 0.93]=3.25$ ). Table 8 presents a comparison between the actual and predicted mean values of each factor for each company and a discussion on significant differences is provided in the following paragraphs.

Firstly, comparisons are discussed for the TR factor predictions for the five companies. Differences between the actual and predicted mean values for the five case studies ranged from -0.62 to 17.57 percent. Thus, with the exception of company 3 , the TE $\rightarrow$ TR path equation could be considered acceptable and reliable for prediction. However, the higher percentage differences for companies 1, 3 and 5, might be considered slightly problematic. These larger differences might be due to the following four reasons, including: (1) the TE factor was not adequately explained by the variables which underpin it; (2) another factor not considered herein or removed by factor analysis may have influence on the TR factor; (3) the case studies did not measure the impact of the government influence (GI) factor on the TR factor; and (4) other project specific affects. The first two reasons could be explained by the removal of the cultural difference variable from the conceptual TT model due to the exploratory factor analysis (EFA) process. This variable may be contained within the TE factor or may be a factor on its own having an overarching impact on a variety of factors. It goes without saying that if the mean values for the GI factor were collected in the model validation process the prediction would be more likely to have improved. The fourth and final reason could be explained by difficult project context similarities for companies 1,3 and 5. These three companies all worked with Japanese transferors. For some reason the TR factor was rated poorly by the Thai respondents, particularly for the TR variable pertaining to the transferors' willingness to transfer technology (Table 6). Perhaps Japanese transferors have a lower willingness to transfer or implement construction technology in Thailand, compared with other transferor nationalities (e.g. German) because they may be beginning to fear that Thai firms may increasingly become direct competitors in the Asian market. Moreover, financial payment delays for company 1 and 3 that both worked on the same construction project could have impacted on the transferor's management practices and approaches (leadership style, ego, etc.).

Secondly, comparisons are discussed for the RB factor predictions for the five companies. The actual and predicted values for RB were very close with differences ranging between 0.29 and 3.51 percent. Thus, the $\mathrm{TR} \rightarrow \mathrm{RB}$ path equation appears to be highly reliable for the prediction of relationship building 
characteristics. Specifically, this validation study provides some solid evidence that appropriate transferor characteristics are essential for building solid relationship between host and foreign project participants. Moreover, transferors who have extensive experience working with indigenous workers, a strong knowledge base and are willing to transfer this knowledge will build a good relationship with local workers. Such relationships will be built on a foundation of mutual trust, good communication and clear understanding.

Lastly, comparisons are discussed for the VA factor predictions for the five companies. Again, the actual and predicted values for VA are very close with differences ranging from -3.72 to 4.64 percent. It appears that the $\mathrm{RB} \rightarrow \mathrm{VA}$ path equation is highly reliable for the prediction of the degree of value added to the host construction sector. The low per cent differences confirm that relationship building is essential for achieving outcomes from the TT process. High mutual trust developed through effective communication and clear understanding between the transferee and transferor will greatly enhance the host firms' knowledge advancement, working practices and overall performance over the long-term.

\section{Conclusion}

The significant interrelationships between the factors in the developed international TT model for construction projects were established utilising structural equation modelling. Moreover, the three significant paths in the developed model, namely, TE $\rightarrow \mathrm{TR}, \mathrm{TR} \rightarrow \mathrm{RB}$ and $\mathrm{RB} \rightarrow \mathrm{VA}$ were selected for validation. The validation phase involved five domestic companies working on four large scale construction projects in Thailand. The respondents comprised Thai construction and engineering professionals who were involved on a current (at time of survey) construction project with a foreign partner and some form of technology (e.g. management skills, construction techniques) was transferred. Comparative analysis between actual and predicted mean values provided evidence that the three significant path equations and their associated standardised path coefficients are reliable for monitoring the TT process and evaluating the degree of value that may result from TT initiatives. Accordingly, government departments and construction businesses in developing and newly industrialised countries are encouraged to use the findings to help guide international 
TT initiatives in their construction industries. The developed model can be utilised by such stakeholders to frame appropriate policy and procedures to ensure improved transfer of explicit and tacit knowledge as well as state-of-the-art construction technologies. In conclusion, it is hoped that this study will encourage construction firms to adopt the proposed model to assist with the measurement and management of implemented TT in construction. Last, it should be noted that the international TT model should be carefully adapted to suit the individual needs of construction firms of developed and newly industrialised countries. In particular, users of the model should firstly undertake a situational analysis to ensure that they select appropriate and reliable measures which accurately reflect true performance in their individual context.

\section{References}

Anderson, J. C. and Gerbing, D. W. (1988), "Structural equation modelling in practice: a review and recommended two-step approach", Psychological Bulletin, Vol. 103, pp. 411-423.

Benedetto, C. A. D., Calantone, R. J. and Zhang, C. (2003), "International technology transfer: model and exploratory study in the People's Republic of China", International Marketing Review, Vol. 20 No. 4, pp. 446-462.

Black, C., Akintoye, A. and Fitzgerald, E. (2000), “An analysis of success factors and benefits of partnering in construction”, International Journal of Project Management, Vol. 18 No. 6, pp. 423-434.

Calantone, R., Lee, M. T. and Gross, A. C. (1990), "Evaluating international technology transfer in a comparative marketing framework”, Journal of Global Marketing, Vol. 3 No. 3, pp. 23-46.

Chacko, G. K. (1986), “International technology transfer for improved production functions”, Engineering Costs and Production Economics, Vol. 10 No. 1, pp. 245-252. 
Chua, D. K. H., Kog, Y. C. and Loh, P. K. (1999), "Critical success factors for different project objectives", Journal of Construction Engineering and Management, Vol. 125 No. 3, pp. 142-150.

Coakes, S. J. (2005), SPSS: Analysis without anguish: version 12.0 for Windows, John Wiley \& Sons Australia Ltd., Sydney, Australia.

Devapriya, K. A. K. and Ganesan, S. (2002), “Technology transfer through subcontracting in developing countries", Building Research and Information, Vol. 30 No. 3, pp. 171-182.

Fang, D. P., Xie, F., Huang, X. Y. and Li, H. (2004), "Factor analysis-based studies on construction workplace safety management in China", International Journal of Project Management, Vol. 22 No. 1, pp. 43-49.

Fisher, T. F. and Ranasinghe, M. (2001), "Culture and foreign company's choice of entry mode: the case of the Singapore building and construction industry", Construction Management and Economics, Vol. 19 No. 4, pp. 343-353.

Ganesan, S. and Kesley, J. (2006), "Technology transfer: international collaboration in Sri Lanka", Construction Management and Economics, Vol. 24 No. 7, pp. 743-753.

Gilbert, M. and Cordey-Hayes, M. (1996), "Understanding the process of knowledge transfer to achieve successful technological innovation”, Technovation, Vol. 16 No. 6, pp. 301-312.

Gold, A. H., Malhotra, A. and Segars, A. H. (2001), "Knowledge management: an organizational capabilities perspective”, Journal of Management Information Systems, Vol. 18 No. 1, pp. 185-214.

Hair, J. F., Anderson, R. E., Tatham, R. L. and Black, W. C. (1998), Multivariate Data Analysis, PrenticeHall, Upper Saddle River, NJ, USA. 
Hatcher, L. (1994), A Step-by-Step Approach to Using the SAS System for Factor Analysis and Structural Equation Modeling, SAS Institution Inc, North Carolina, USA.

ITS (2001), Structural Equation Modeling using AMOS: An Introduction. The University of Texas at Austin, Texas, USA.

Kaynak, H. (2003), "The relationship between total quality management practices and their effects on firm performance", Journal of Operations Management, Vol. 21 No. 4, pp. 405-435.

Kumaraswamy, M. M. and Shrestha, G. B. (2002), "Targeting 'technology exchange' for faster organisational and industry development", Building Research and Information, Vol. 30 No. 3, pp. 183-195.

Lin, B. W. and Berg, D. (2001), "Effects of cultural difference on technology transfer projects: an empirical study of Taiwanese manufacturing companies", International Journal of Project Management, Vol. 19 No. 5, pp. 287-293.

Makilouko, M. (2004), "Coping with multicultural projects: the leadership styles of finish project managers", International Journal of Project Management, Vol. 22 No. 5, pp. 387-396.

Malik, K. (2002), "Aiding the technology manager: a conceptual model for intra-firm technology transfer", Technovation, Vol. 22 No. 7, pp. 427-436.

Marton, K. (1986), Multinationals, Technology and Industrialization, Lexington, MA, USA.

Ofori, G. (2000), "Globalization and construction industry development: research opportunities", Construction Management and Economics, Vol. 18 No. 3, pp. 257-262. 
Ragu-Nathan, B. S., Apigian, C. H., Ragu-Nathan, T. S. and Tu, Q. (2004), "A path analytic study of the effect of top management support for information systems performance", Omega, Vol. 32 No. 6, pp. $459-471$.

Saad, M., Cicmil, S. and Greenwood, M. (2002), "Technology transfer projects in developing countries furthering the project management perspectives", International Journal of Project Management, Vol. 20 No. 8, pp. 617-625.

San, M. M. (2004), "Technology transfer a need for development of building sector", (available at http://www.myanmar.com/myanmartimes/MyanmarTimes12-235/025.htm.)

Simkoko, E. E. (1992), "Managing international construction projects for competence development within local firms", International Journal of Project Management, Vol. 10 No. 1, pp. 12-22.

Stewart, R. A. (2007), "IT enhanced project information management in construction: pathways to improved performance and strategic competitiveness", Automation in Construction, Vol. 16 No. 4, pp. 511517.

UNCTAD. (1979), "Draft international code of conduct on the transfer of technology", United Nations Conference on Trade and Development, Geneva.

Wang, P., Tong, T. W. and Koh, C. P. (2004), “An integrated model of knowledge transfer from MNC parent to China subsidiary", Journal of World Business, Vol. 39 No. 2, pp. 168-182.

Waroonkun, T., and Stewart, R. A. (2007), "Modelling the international technology transfer process in construction projects: evidence from Thailand", Journal of Technology Transfer, forthcoming [accepted March, 2007]. 
Waroonkun, T. (2007), Modelling international technology transfer in Thai construction projects, PhD Thesis, Griffith University-Gold Coast Campus, Gold Coast, Australia.

Zain, M., Rose, R. C., Abdullah, I. and Masrom, M. (2005), "The relationship between information technology acceptance and organizational agility in Malaysia”, Information \& Management, Vol. 42 No. 6, pp. 829-839. 
Table 1 Construct and variable mean and standard deviation

\begin{tabular}{|c|c|c|c|c|c|}
\hline Code & Descriptions & $\begin{array}{l}\text { Mean } \\
\text { Column A }\end{array}$ & $\begin{array}{l}\text { Std. Dev. } \\
\text { Column A }\end{array}$ & $\begin{array}{l}\text { Mean } \\
\text { Column B }\end{array}$ & $\begin{array}{l}\text { Std. Dev. } \\
\text { Column B }\end{array}$ \\
\hline \multicolumn{6}{|c|}{ Enablers } \\
\hline E1 & Transfer Environment & 3.44 & 0.93 & 3.29 & 0.81 \\
\hline E 1.1 & Complexity level & 3.48 & 0.82 & 3.24 & 0.65 \\
\hline E 1.2 & Mode of transfer & 3.36 & 0.84 & 3.36 & 0.74 \\
\hline E 1.3 & Government policy & 3.41 & 1.04 & 3.26 & 0.87 \\
\hline E 1.4 & Government enforcement & 3.49 & 1.00 & 3.29 & 0.98 \\
\hline E2 & Learning Environment & 3.84 & 0.85 & 3.47 & 0.89 \\
\hline E 2.1 & Culture & 3.39 & 1.04 & 3.03 & 0.88 \\
\hline E 2.2 & Trust & 3.92 & 0.83 & 3.44 & 0.91 \\
\hline E 2.3 & Understanding & 3.96 & 0.97 & 3.51 & 1.00 \\
\hline E 2.4 & Communication & 4.28 & 0.81 & 3.92 & 0.88 \\
\hline E 2.5 & Commitment & 3.75 & 0.81 & 3.52 & 0.84 \\
\hline E 2.6 & Teamwork & 4.04 & 0.76 & 3.64 & 0.83 \\
\hline E 2.7 & Training & 4.10 & 0.79 & 3.70 & 0.94 \\
\hline E 2.8 & Local sub-contractors & 3.28 & 0.95 & 3.04 & 0.88 \\
\hline E 2.9 & Supervision & 3.85 & 0.73 & 3.44 & 0.87 \\
\hline E3 & Transferor Characteristic & 3.97 & 0.79 & 3.63 & 0.86 \\
\hline E 3.1 & Willingness to implement & 3.99 & 0.82 & 3.57 & 0.98 \\
\hline E 3.2 & Degree of experience & 4.07 & 0.78 & 3.65 & 0.79 \\
\hline E 3.3 & Transferor management & 3.81 & 0.77 & 3.61 & 0.84 \\
\hline E 3.4 & Knowledge base & 4.01 & 0.77 & 3.67 & 0.83 \\
\hline E4 & Transferee Characteristic & 3.93 & 0.80 & 3.63 & 0.80 \\
\hline E 4.1 & Willingness to learn & 4.07 & 0.85 & 3.72 & 0.83 \\
\hline E 4.2 & Degree of experience & 3.88 & 0.82 & 3.62 & 0.82 \\
\hline E 4.3 & Transferee management & 3.76 & 0.79 & 3.54 & 0.77 \\
\hline E 4.4 & Knowledge base & 4.02 & 0.74 & 3.64 & 0.76 \\
\hline \multicolumn{6}{|c|}{ Value creation } \\
\hline O1 & Economic advancement & 3.95 & 0.77 & 3.55 & 0.83 \\
\hline O 1.1 & Competitiveness & 3.94 & 0.77 & 3.50 & 0.81 \\
\hline O 1.2 & Performance & 3.95 & 0.77 & 3.59 & 0.85 \\
\hline $\mathrm{O} 2$ & Knowledge advancement & 3.87 & 0.76 & 3.46 & 0.88 \\
\hline O 2.1 & $\begin{array}{l}\text { Improved knowledge } \\
\text { Improved working }\end{array}$ & 3.77 & 0.82 & 3.34 & 0.89 \\
\hline O 2.2 & practices & 3.93 & 0.75 & 3.54 & 0.92 \\
\hline O 2.3 & Long-term adoption & 3.92 & 0.71 & 3.49 & 0.84 \\
\hline O3 & Project performance & 3.72 & 0.80 & 3.40 & 0.86 \\
\hline O 3.1 & Financial performance & 3.47 & 0.84 & 3.24 & 0.90 \\
\hline O 3.2 & Schedule performance & 3.69 & 0.79 & 3.44 & 0.81 \\
\hline $\mathrm{O} 3.3$ & Quality standards & 4.01 & 0.77 & 3.52 & 0.86 \\
\hline
\end{tabular}

Note:

Column A Description: Importance of Enabler for TT

Column B Description: Perceived Success/ Effectiveness of Enabler 
Table 2 Varimax rotated factor loading for the eight-factor solution

\begin{tabular}{|c|c|c|}
\hline Factor & Items (identifying questions) & Factor Loading \\
\hline $\begin{array}{l}\text { Enablers } \\
\text { 1. Technology Characteristics } \\
\text { Variance }=3.53 \% ; \\
\text { Eigenvalue }=0.71 \\
\text { Cronbach's } \alpha=0.57\end{array}$ & $\begin{array}{l}\text { Complexity level } \\
\text { Construction mode of transfer }\end{array}$ & $\begin{array}{l}0.80 \\
0.84\end{array}$ \\
\hline $\begin{array}{l}\text { 2. Government Influence } \\
\text { Variance }=5.07 \% \\
\text { Eigenvalue }=1.01 \\
\text { Cronbach's } \alpha=0.81\end{array}$ & $\begin{array}{l}\text { Government policy } \\
\text { Government enforcement }\end{array}$ & $\begin{array}{l}0.90 \\
0.88\end{array}$ \\
\hline $\begin{array}{l}\text { 3. Relationship Building } \\
\text { Variance }=9.87 \% \\
\text { Eigenvalue }=1.97 \\
\text { Cronbach's } \alpha=0.79\end{array}$ & $\begin{array}{l}\text { Trust } \\
\text { Understanding } \\
\text { Communication }\end{array}$ & $\begin{array}{l}0.69 \\
0.75 \\
0.71\end{array}$ \\
\hline $\begin{array}{l}\text { 4. Transferor Characteristics } \\
\text { Variance }=34.97 \% \\
\text { Eigenvalue }=6.99 \\
\text { Cronbach's } \alpha=0.86\end{array}$ & $\begin{array}{l}\text { Willingness to implement } \\
\text { Transferor's degree of experience } \\
\text { Transferor management } \\
\text { Knowledge base }\end{array}$ & $\begin{array}{l}0.64 \\
0.76 \\
0.79 \\
0.72\end{array}$ \\
\hline $\begin{array}{l}\text { 5. Transferee Characteristics } \\
\text { Variance }=8.52 \% \\
\text { Eigenvalue }=1.70 \\
\text { Cronbach's } \alpha=0.77\end{array}$ & $\begin{array}{l}\text { Transferee's degree of experience } \\
\text { Transferee management } \\
\text { Knowledge base }\end{array}$ & $\begin{array}{l}0.84 \\
0.69 \\
0.65\end{array}$ \\
\hline $\begin{array}{l}\text { Value Creation } \\
\text { 6. Economic Advancement } \\
\text { Variance }=6.55 \% \\
\text { Eigenvalue }=1.31 \\
\text { Cronbach's } \alpha=0.83\end{array}$ & $\begin{array}{l}\text { Competitiveness } \\
\text { Performance }\end{array}$ & $\begin{array}{l}0.83 \\
0.79\end{array}$ \\
\hline $\begin{array}{l}\text { 7. Knowledge Advancement } \\
\text { Variance }=4.47 \% \\
\text { Eigenvalue }=0.89 \\
\text { Cronbach's } \alpha=0.77\end{array}$ & $\begin{array}{l}\text { Improved knowledge } \\
\text { Improved working practices }\end{array}$ & $\begin{array}{l}0.82 \\
0.69\end{array}$ \\
\hline $\begin{array}{l}\text { 8. Project Performance } \\
\text { Variance }=4.34 \% \\
\text { Eigenvalue }=0.87 \\
\text { Cronbach's } \alpha=0.70\end{array}$ & $\begin{array}{l}\text { Financial performance } \\
\text { Schedule performance }\end{array}$ & $\begin{array}{l}0.77 \\
0.80\end{array}$ \\
\hline
\end{tabular}


Table 3 Varimax rotated factor loading for the single outcome factor solution

\begin{tabular}{lll}
\hline Factor & Items (identifying questions) & Factor Loading \\
\hline Value creation & & \\
1. TT value added & Competitiveness & 0.78 \\
Variance $=55.71 \%$ & Performance & 0.81 \\
Eigenvalue $=3.34$ & Improved knowledge & 0.74 \\
Cronbach's $\alpha=0.84$ & Working practices & 0.76 \\
& Financial performance & 0.71 \\
& Schedule performance & 0.68 \\
\hline
\end{tabular}


Table 4 Measurement model results

\begin{tabular}{|c|c|c|c|}
\hline $\begin{array}{l}\text { Factor } \\
\text { Variable Description }\end{array}$ & $\begin{array}{l}\text { Standardised } \\
\text { Regression } \\
\text { Weight }\end{array}$ & $t$-value & $R^{2}$ \\
\hline \multicolumn{4}{|l|}{ Technology Characteristics } \\
\hline Complexity level & $1.06^{N S}$ & 1.64 & 1.12 \\
\hline Construction mode of transfer & $0.38^{N S}$ & - & 0.15 \\
\hline \multicolumn{4}{|l|}{ Government Influence } \\
\hline Government policy & 0.74 & - & 0.55 \\
\hline Government enforcement & 0.93 & 5.54 & 0.86 \\
\hline \multicolumn{4}{|l|}{ Relationship Building } \\
\hline Trust & 0.69 & 8.97 & 0.47 \\
\hline Understanding & 0.86 & - & 0.73 \\
\hline Communication & 0.73 & 9.65 & 0.54 \\
\hline \multicolumn{4}{|l|}{ Transferor Characteristics } \\
\hline Willingness to implement & 0.81 & 10.54 & 0.66 \\
\hline Transferor's degree of experience & 0.78 & 10.07 & 0.61 \\
\hline Transferor management & 0.77 & - & 0.59 \\
\hline Knowledge base & 0.77 & 9.90 & 0.59 \\
\hline \multicolumn{4}{|l|}{ Transferee Characteristics } \\
\hline Transferee's degree of experience & 0.67 & - & 0.45 \\
\hline Transferee management & 0.79 & 7.81 & 0.63 \\
\hline Knowledge base & 0.72 & 7.38 & 0.52 \\
\hline \multicolumn{4}{|l|}{ TT Value Added } \\
\hline Competitiveness & 0.65 & - & 0.43 \\
\hline Performance & 0.68 & 9.56 & 0.46 \\
\hline Improved knowledge & 0.65 & 6.26 & 0.42 \\
\hline Working practices & 0.74 & 6.92 & 0.54 \\
\hline Financial performance & 0.62 & 6.23 & 0.38 \\
\hline Schedule performance & 0.57 & 5.79 & 0.32 \\
\hline
\end{tabular}

- Fixed for estimation; NS: Not significant. 
Table 5 Standardised path coefficients and structural equations

\begin{tabular}{lllll}
\hline Paths & Structural equations & Coefficient & $t$ & $R^{2}$ \\
\hline Path model & & & & \\
$\mathrm{GI} \rightarrow \mathrm{TE}$ & $Z_{T E}=0.19\left(Z_{G I}\right)$ & $\gamma=0.19$ & $1.92^{* *}$ & 0.04 \\
$\mathrm{GI} \rightarrow \mathrm{TR}$ & $Z_{T R}=0.28\left(\mathrm{Z}_{G I}\right)+0.70\left(Z_{T E}\right)$ & $\gamma=0.28$ & $3.72^{* * *}$ & 0.64 \\
$\mathrm{TE} \rightarrow \mathrm{TR}$ & & $\beta=0.70$ & $6.95^{* * *}$ & \\
$\mathrm{TR} \rightarrow \mathrm{RB}$ & $Z_{R B}=0.81\left(Z_{T R}\right)$ & $\beta=0.81$ & $7.65^{* * *}$ & 0.65 \\
$\mathrm{RB} \rightarrow \mathrm{VA}$ & $\mathrm{Z}_{V A}=0.66\left(Z_{R B}\right)$ & $\beta=0.66$ & $5.15^{* * *}$ & 0.44 \\
$\mathrm{Three} \mathrm{significant} \mathrm{paths} \mathrm{utilised} \mathrm{for} \mathrm{path} \mathrm{model} \mathrm{validation}$ & & \\
$\mathrm{TE} \rightarrow \mathrm{TR}$ & $Z_{T R}=0.70\left(Z_{T E}\right)$ & $\gamma=0.70$ & $6.95^{* * *}$ & 0.56 \\
$\mathrm{TR} \rightarrow \mathrm{RB}$ & $Z_{R B}=0.81\left(Z_{T R}\right)$ & $\beta=0.81$ & $7.65^{* * *}$ & 0.65 \\
$\mathrm{RB} \rightarrow \mathrm{VA}$ & $\mathrm{Z}_{V A}=0.66\left(Z_{R B}\right)$ & $\beta=0.66$ & $5.15^{* * *}$ & 0.44 \\
\hline
\end{tabular}

**p $<0.05 ; * * * p<0.01$.

Paths: Government Influence (GI) $\rightarrow$ Transferee Characteristics (TE); Government Influence (GI) $\rightarrow$ Transferor Characteristics (TR); Transferee Characteristics (TE) $\rightarrow$ Transferor Characteristics (TR); Transferor Characteristics $(\mathrm{TR}) \rightarrow$ Relationship Building (RB); and Relationship Building (RB) $\rightarrow$ TT Value Added (VA). 
Table 6 Mean and standard deviation values for the primary and case studies

\begin{tabular}{|c|c|c|c|c|c|c|c|c|c|c|c|c|c|}
\hline \multirow{2}{*}{ Code } & \multirow{2}{*}{ Descriptions } & \multicolumn{2}{|c|}{ Primary Study } & \multicolumn{2}{|c|}{ Company 1} & \multicolumn{2}{|c|}{ Company 2} & \multicolumn{2}{|c|}{ Company 3} & \multicolumn{2}{|c|}{ Company 4} & \multicolumn{2}{|c|}{ Company 5} \\
\hline & & Mean & S.D. & Mean & S.D. & Mean & S.D. & Mean & S.D. & Mean & S.D. & Mean & S.D. \\
\hline$R B$ & Relationship building & 3.62 & 0.93 & 3.15 & 0.94 & 3.49 & 0.72 & 3.02 & 0.78 & 3.25 & 1.00 & 3.13 & 0.67 \\
\hline RB1 & Trust & 3.44 & 0.91 & 3.07 & 0.89 & 3.63 & 0.73 & 3.03 & 0.74 & 3.11 & 0.69 & 3.38 & 0.72 \\
\hline RB2 & Understanding & 3.51 & 1.00 & 3.04 & 0.94 & 3.63 & 0.82 & 3.09 & 0.88 & 3.41 & 1.80 & 3.08 & 0.77 \\
\hline RB3 & Communication & 3.92 & 0.88 & 3.33 & 1.00 & 3.20 & 0.61 & 2.94 & 0.71 & 3.22 & 0.52 & 2.92 & 0.51 \\
\hline$T R$ & Transferor characteristics & 3.63 & 0.86 & 3.21 & 1.03 & 3.49 & 0.58 & 2.96 & 0.90 & 3.25 & 0.80 & 3.19 & 0.82 \\
\hline TR1 & Willingness to implement & 3.57 & 0.98 & 2.96 & 1.02 & 3.13 & 0.46 & 2.27 & 0.81 & 3.26 & 0.59 & 2.92 & 0.82 \\
\hline TR2 & Degree of experience & 3.65 & 0.79 & 3.48 & 1.05 & 3.97 & 0.77 & 3.33 & 1.06 & 3.33 & 0.81 & 3.21 & 0.79 \\
\hline TR3 & Transferor management & 3.61 & 0.84 & 2.96 & 1.00 & 3.30 & 0.53 & 2.94 & 0.91 & 3.19 & 1.02 & 3.38 & 0.69 \\
\hline TR4 & Knowledge base & 3.67 & 0.83 & 3.44 & 1.06 & 3.57 & 0.57 & 3.30 & 0.82 & 3.22 & 0.78 & 3.25 & 0.96 \\
\hline$T E$ & Transferee characteristics & 3.60 & 0.78 & 3.42 & 0.63 & 3.20 & 0.54 & 3.41 & 0.92 & 3.08 & 0.75 & 3.42 & 0.87 \\
\hline TE1 & Degree of experience & 3.62 & 0.82 & 3.33 & 0.61 & 3.30 & 0.75 & 3.39 & 0.96 & 3.04 & 0.92 & 3.38 & 0.79 \\
\hline TE2 & Transferee management & 3.54 & 0.77 & 3.41 & 0.50 & 3.17 & 0.52 & 3.33 & 0.91 & 3.00 & 0.68 & 3.33 & 0.98 \\
\hline TE3 & Knowledge base & 3.64 & 0.76 & 3.52 & 0.77 & 3.13 & 0.35 & 3.52 & 0.90 & 3.19 & 0.64 & 3.54 & 0.84 \\
\hline$V A$ & TT value added & 3.44 & 0.86 & 3.02 & 0.96 & 3.49 & 0.56 & 3.04 & 1.03 & 3.22 & 0.74 & 3.16 & 0.71 \\
\hline EA1 & Competitiveness & 3.50 & 0.81 & 3.22 & 1.09 & 3.70 & 0.48 & 3.18 & 1.08 & 3.33 & 0.71 & 3.13 & 0.83 \\
\hline EA2 & Performance & 3.59 & 0.85 & 3.33 & 1.00 & 3.80 & 0.63 & 3.36 & 1.03 & 3.56 & 0.73 & 3.25 & 0.46 \\
\hline KA1 & Improved knowledge & 3.34 & 0.89 & 3.15 & 0.89 & 3.33 & 0.54 & 3.18 & 0.79 & 3.07 & 0.53 & 3.08 & 0.57 \\
\hline KA2 & Working practices & 3.54 & 0.92 & 3.19 & 0.91 & 3.63 & 0.62 & 3.24 & 1.11 & 3.33 & 0.79 & 3.25 & 0.80 \\
\hline PP1 & Financial performance & 3.24 & 0.90 & 2.67 & 1.00 & 3.10 & 0.57 & 2.82 & 0.98 & 2.89 & 0.60 & 2.88 & 0.83 \\
\hline PP2 & Schedule performance & 3.44 & 0.81 & 2.56 & 0.88 & 3.40 & 0.52 & 2.45 & 1.21 & 3.11 & 1.05 & 3.38 & 0.74 \\
\hline
\end{tabular}


Table 7 Actual mean equivalent and predicted $Z$ scores

\begin{tabular}{llllll}
\hline \multirow{2}{*}{ Title } & Descriptions & \multicolumn{4}{c}{ Factors } \\
\cline { 3 - 6 } Primary study & Mean & 3.60 & 3.63 & 3.62 & 3.44 \\
\cline { 2 - 5 } Company code (case studies) & S.D. & 0.78 & 0.86 & 0.93 & 0.86 \\
& CO.1 (Mean) & 3.42 & 3.21 & 3.15 & 3.02 \\
& CO.2 (Mean) & 3.20 & 3.49 & 3.49 & 3.49 \\
& CO.3 (Mean) & 3.41 & 2.96 & 3.02 & 3.04 \\
& CO.4 (Mean) & 3.08 & 3.25 & 3.25 & 3.22 \\
& CO.5 (Mean) & 3.42 & 3.19 & 3.13 & 3.16 \\
& $\mathrm{Z}_{\mathrm{C} 0.1}$ & -0.23 & -0.49 & -0.51 & -0.49 \\
& $\mathrm{Z}_{\mathrm{C} 0.2}$ & -0.51 & -0.16 & -0.14 & 0.06 \\
& $\mathrm{Z}_{\mathrm{C} 0.3}$ & -0.24 & -0.78 & -0.65 & -0.47 \\
& $\mathrm{Z}_{\mathrm{C} 0.4}$ & -0.67 & -0.44 & -0.40 & -0.26 \\
& $\mathrm{Z}_{\mathrm{C} 0.5}$ & -0.23 & -0.51 & -0.53 & -0.33 \\
& $\mathrm{Z}_{\mathrm{C} 0.1}$ & - & -0.16 & -0.40 & -0.33 \\
& $\mathrm{Z}_{\mathrm{C} 0.2}$ & - & -0.36 & -0.13 & -0.09 \\
& $\mathrm{Z}_{\mathrm{C} 0.3}$ & - & -0.17 & -0.63 & -0.43 \\
& $\mathrm{Z}_{\mathrm{C} 0.4}$ & - & -0.47 & -0.36 & -0.26 \\
& $\mathrm{Z}_{\mathrm{C} 0.5}$ & - & -0.16 & -0.41 & -0.35 \\
\hline
\end{tabular}


Table 8 Comparison between the actual and predicted mean values of TR, RB and VA

\begin{tabular}{lllll}
\hline Company & $\begin{array}{l}\text { Actual } \\
\text { value }\end{array}$ & $\begin{array}{l}\text { Predicted } \\
\text { value }\end{array}$ & $\begin{array}{l}\text { Difference } \\
\text { (raw) }\end{array}$ & $\begin{array}{l}\text { Difference } \\
\text { (per cent) }\end{array}$ \\
\hline $\begin{array}{l}\text { Transferor characteristics (TR) } \\
\text { Company 1 }\end{array}$ & & & & \\
Company 2 & 3.21 & 3.49 & 0.28 & 8.72 \\
Company 3 & 3.49 & 3.32 & -0.17 & -4.87 \\
Company 4 & 2.96 & 3.48 & 0.52 & 17.57 \\
Company 5 & 3.25 & 3.23 & -0.02 & -0.62 \\
Relationship building (RB) & 3.19 & 3.49 & 0.30 & 9.40 \\
Company 1 & & & & \\
Company 2 & 3.15 & 3.25 & 0.10 & 3.17 \\
Company 3 & 3.49 & 3.50 & 0.01 & 0.29 \\
Company 4 & 3.02 & 3.03 & 0.01 & 0.33 \\
Company 5 & 3.25 & 3.29 & 0.04 & 1.23 \\
TT value added (VA) & 3.13 & 3.24 & 0.11 & 3.51 \\
Company 1 & & & & \\
Company 2 & 3.02 & 3.16 & 0.14 & 4.64 \\
Company 3 & 3.49 & 3.36 & -0.13 & -3.72 \\
Company 4 & 3.04 & 3.07 & 0.03 & 0.99 \\
Company 5 & 3.22 & 3.22 & 0.00 & 0.00 \\
\hline
\end{tabular}




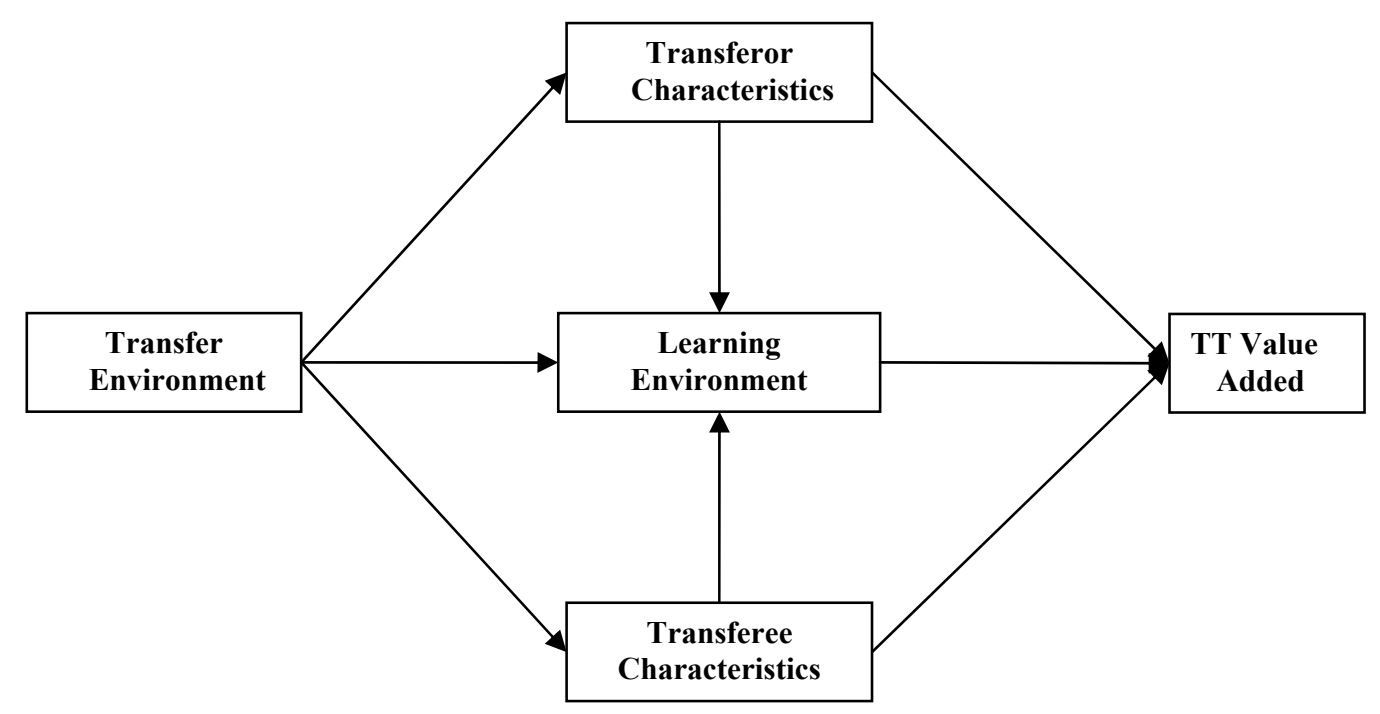

Figure 1 Conceptual model for international TT in construction projects

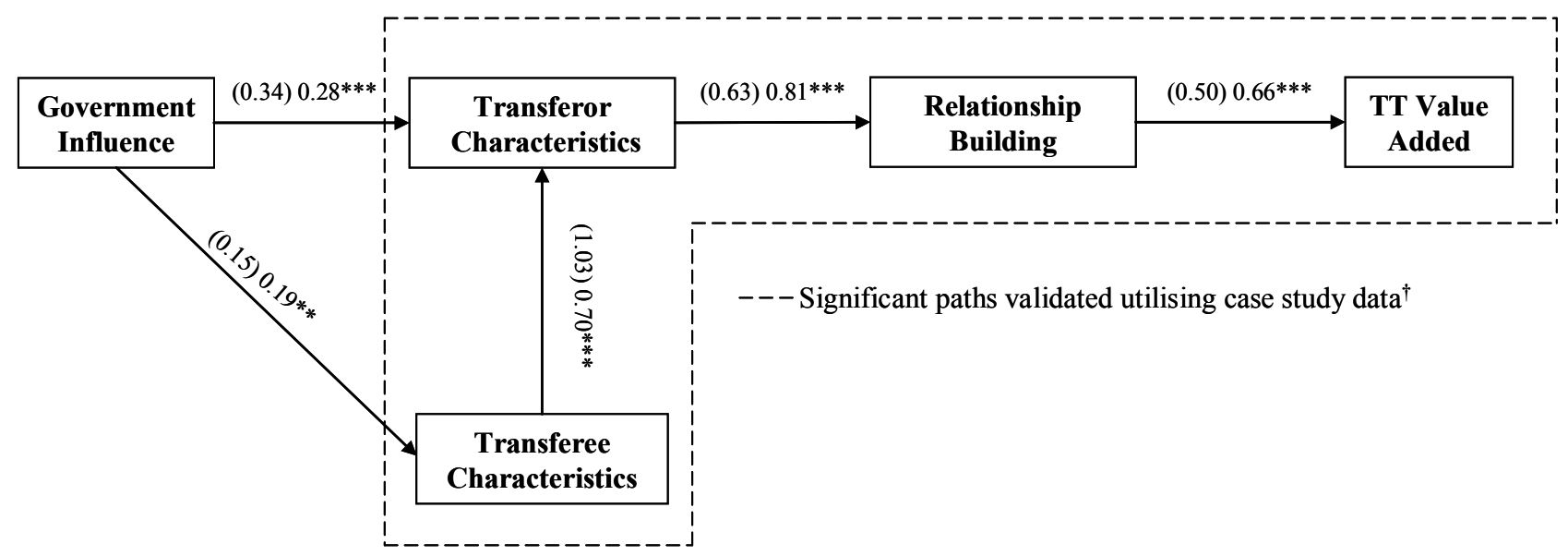

Note: Value in parentheses are unstandardised path coefficients, values not in parentheses are standardised path coefficients $(* * p<0.05 ; * * * p<0.01)$. ${ }^{\dagger}$ Significant paths were valuated utilising data collected from case studies on five Thai companies where technology was transferred from a foreign partner (see Table 5).

Figure 2 Path model for international TT in construction projects 